\title{
Chapter 11 \\ Impacts of Wind Energy Development on Bats: A Global Perspective
}

\author{
Edward B. Arnett, Erin F. Baerwald, Fiona Mathews, Luisa Rodrigues, \\ Armando Rodríguez-Durán, Jens Rydell, Rafael Villegas-Patraca \\ and Christian C. Voigt
}

\begin{abstract}
Wind energy continues to be one of the fastest growing renewable energy sources under development, and while representing a clean energy source, it is not environmentally neutral. Large numbers of bats are being killed at utilityscale wind energy facilities worldwide, raising concern about cumulative impacts of wind energy development on bat populations. We discuss our current state of knowledge on patterns of bat fatalities at wind facilities, estimates of fatalities, mitigation efforts, and policy and conservation implications. Given the magnitude and extent of fatalities of bats worldwide, the conservation implications of understanding and mitigating bat fatalities at wind energy facilities are critically important and should be proactive and based on science rather than being reactive and arbitrary.
\end{abstract}

\footnotetext{
E.B. Arnett $(\square)$

Department of Natural Resource Management, Texas Tech University, Lubbock, TX, USA

e-mail: earnett@trcp.org

E.F. Baerwald

Department of Biological Sciences, University of Calgary, Calgary, Canada

F. Mathews

College of Life and Environmental Sciences, University of Exeter, Exeter, UK

L. Rodrigues

Instituto da Conservação da Natureza e das Florestas, Lisbon, Portugal

A. Rodríguez-Durán

Universidad Interamericana, Bayamón, Puerto Rico

J. Rydell

Biology Department, Lund University, 22362 Lund, Sweden
}

(C) The Author(s) 2016 


\subsection{Introduction}

Developing renewable energy alternatives has become a global priority, owing to long-term environmental impacts from the use of fossil fuels, coupled with a changing climate (Schlesinger and Mitchell 1987; McLeish 2002; Inkley et al. 2004) and because of growing concerns about negative effects from the use of nuclear power (Voigt et al. 2015a). Wind power is one of the fastest growing renewable energy sources worldwide (Fig. 11.1), in part due to recent costcompetitiveness with conventional energy sources, technological advances, and tax incentives (Bernstein et al. 2006). Although presently wind power contributes only about $4 \%$ of the global electricity demand, some countries provide greater than $20 \%$ of their demand from wind (e.g., Denmark [34 \%] and Spain and Portugal [21\%]; World Wind Energy Association, www.wwindea.org). By the end of 2013, the Global Wind Energy Council reported that 318,105 MW of wind power capacity was installed worldwide (http://www.gwec.net/wp-content/uploads/2014/04/5_17-1_global-installed-wind-power-capacity_regionaldistribution.jpg). The World Wind Energy Association (http://www.wwindea.org) projects that by 2020 , more than $700,000 \mathrm{MW}$ could be installed globally.

Wind energy development is not environmentally neutral, and impacts to wildlife and their habitats have been documented and are of increasing concern. Wind energy development affects wildlife through direct mortality and indirectly through impacts on habitat structure and function (Arnett et al. 2007; Arnett 2012; NRC 2007; Strickland et al. 2011). Bats are killed by blunt force trauma or barotrauma and may also suffer from inner ear damage and other injuries not readily noticed by examining carcasses in the field (Baerwald et al. 2008; Grodsky et al. 2011; Rollins et al. 2012; Fig. 11.2). Kunz et al (2007a) proposed several hypotheses that may explain why bats are killed and some of these ideas have subsequently been discussed by others (e.g., Cryan and Barclay 2009; Rydell et al 2010a). Collisions at turbines do not appear to be chance events, and bats probably are attracted to turbines either directly, as turbines may resemble roosts (Cryan 2008), or indirectly, because turbines attract insects on which the bats feed (Rydell et al. 2010b). Horn et al. (2008) and Cryan et al. (2014) provide video evidence of possible attraction of bats to wind turbines.

Regardless of causal mechanisms, bat fatalities raise serious concerns about population-level impacts because bats are long-lived and have exceptionally low reproductive rates, and their population growth is relatively slow, which

\footnotetext{
R. Villegas-Patraca

Unidad de Servicios Profesionales Altamente Especializados, Instituto de Ecología, Coatepec, Veracruz, Mexico

C.C. Voigt

Department of Evolutionary Ecology, Leibniz Institute for Zoo and Wildlife Research, Berlin, Germany
} 


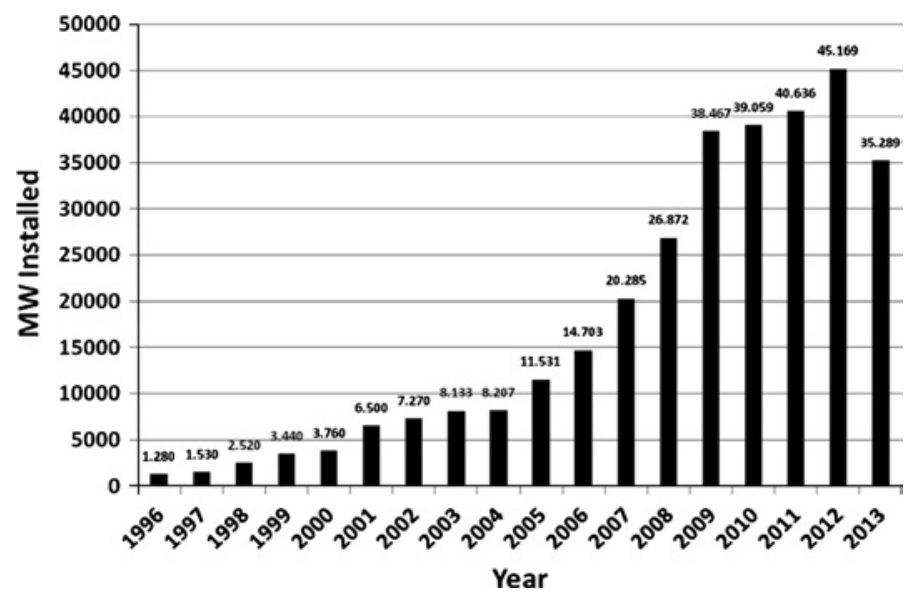

Fig. 11.1 Annual installed global wind energy capacity (MW) from 1996-2013 (modified from the Global Wind Energy Council, http://www.gwec.net/global-figures/graphs/)
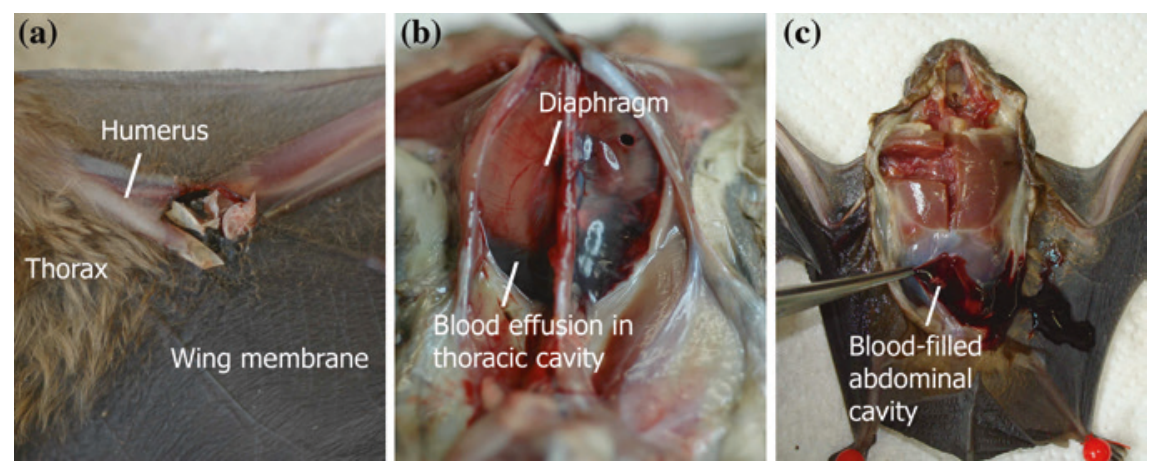

Fig. 11.2 Blunt force trauma (a) and barotrauma (b, c) in three noctule bats (Nyctalus noctula) killed at wind turbine in Germany. a Ventral view of an open fracture of the left humerus at the height of the elbow joint. b Ventral view of the opened abdominal cavity with blood effusion in the thoracic cavity visible behind the diaphragm (hemothorax). c Ventral view of opened carcass without bone fractures, but severe bleeding in the abdominal cavity (hemoabdomen) (picture courtesy: Gudrun Wibbelt, IZW)

limits their ability to recover from declines and maintain sustainable populations (Barclay and Harder 2003). Additionally, other sources of mortality cumulatively threaten many populations. For example, white-nosed syndrome causes devastating declines in bat populations in the USA and Canada (e.g., Frick et al. 2010), and national programs for improving insulation of buildings, particularly in Northern Europe, cause losses of roosting opportunities for bats such as the common pipistrelle (Pipistrellus pipistrellus; Voigt et al. 2016). Thus, high wind turbine mortality poses a serious threat to bats unless solutions are developed and 
implemented (Arnett and Baerwald 2013). In this chapter, we build on previous reviews of existing information (e.g., Arnett et al. 2008; Rydell et al. 2010a; Arnett and Baerwald 2013; EUROBATS 2014), synthesize information on bat fatalities at wind energy facilities worldwide, discuss unifying themes and policy and conservation implications, and offer insights for future directions of research and mitigation of bat fatalities at wind facilities.

\subsection{Composition and Estimates of Bat Fatalities}

We present information on estimates of bat fatalities as reported in published literature or publically available reports, but caution that studies had varying levels of effort, used different estimators (e.g., Huso 2011; Korner-Nievergelt et al. 2013) and different methods to quantify bias (Arnett et al. 2008; Strickland et al. 2011), thus biasing estimates. Also, most estimators fail to adequately account for unsearched area near turbines (Huso and Dalthorp 2013), which further biases estimates. Some studies report fatalities/turbine and others fatalities/MW of installed capacity. As such, data presented here offer a general and relative sense of fatalities within and among continents and do not represent quantitative comparisons.

\subsubsection{North America}

From 2000 to 2011 in the USA and Canada, annual bat fatality rates were highest at facilities located in the Northeastern Deciduous Forest (6.1-10.5 bats/MW; Fig. 11.3) and Midwestern Deciduous Forest-Agricultural (4.9-11.0 bats/MW) regions defined by Arnett and Baerwald (2013: 438). Average fatality rate in the

Fig. 11.3 Wind energy facilities on forested ridges in the eastern USA have consistently documented high fatality rates of bats (photograph by E.B. Arnett)

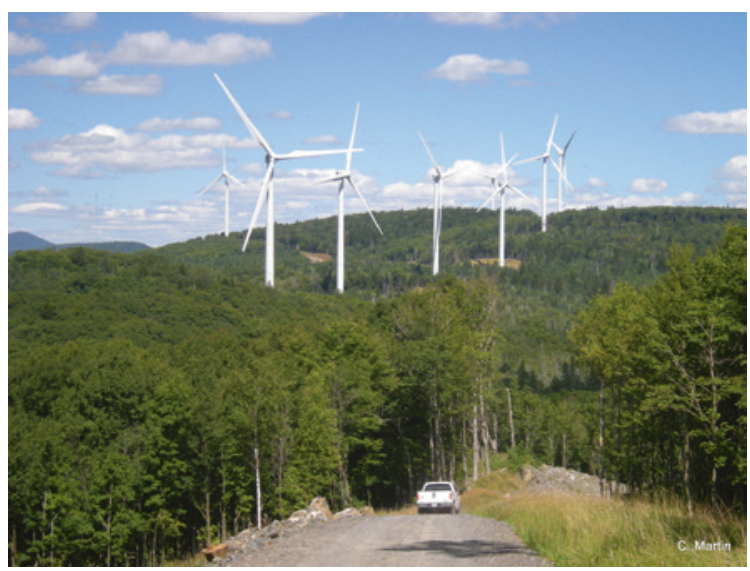


Great Plains region was moderately high (6 bats/MW, $95 \%$ CI: 4.0-8.1 bats/MW), while the Great Basin/Southwest Desert region (1.0-1.8 bats/MW) consistently reports the least variable and lowest fatality rates for bats (Arnett et al. 2008; Arnett and Baerwald 2013; Johnson 2005). Wind energy facilities in this region occur in habitats generally offering few roosting resources, possibly (but untested) poor foraging opportunities, and may not be in migratory pathways, thus rendering these sites less risky to bats (Arnett and Baerwald 2013). However, facilities in other regions report high fatality rates of bats where there are large expanses of prairie and agricultural lands with few roosting resources, foraging opportunities, and likely migratory routes (e.g., Summer view Alberta, Canada, 8-14.6 bats/MW; Baerwald et al. 2008). Thus, current patterns in the Great Basin/Southwest region reported by Arnett and Baerwald (2013) may simply reflect biased reporting and an absence of evidence as opposed to evidence of absence (Huso and Dalthorp 2013).

Twenty-one of the 47 species of bats known to occur in the USA and Canada have been reported killed at wind energy facilities, and fatalities are skewed toward migratory species often referred to as "tree bats" that include hoary bats (Lasiurus cinereus; $38 \%$ ), eastern red bats (Lasiurus borealis; $22 \%$ ), and silverhaired bats (Lasionycteris noctivagans; $18.4 \%$ ) that comprise a total of $78.4 \%$ of the recovered bat turbine fatalities in the USA and Canada (Arnett and Baerwald 2013). However, other species also are affected, sometimes seriously. Fatalities of the cave-living Brazilian free-tailed bats (Tadarida brasiliensis) are quite frequent in the southern USA during the maternity period in summer (Miller 2008; Piorkowski and O'Connell 2010). In the USA, two species listed as threatened or endangered under the Endangered Species Act also have been killed by turbines, the Indiana bat (Myotis sodalis) and Hawaiian hoary bat (Lasiurus cinereus semotus; Arnett and Baerwald 2013).

In the Oaxacan Isthmus region of Mexico, 32 of the 42 species of bats known to occupy this region (García-Grajales and Silva 2012; Briones-Salas et al. 2013) were found killed (Villegas-Patraca et al. 2012). These bats belonged to five different families (Mormoopidae, Molossidae, Vespertilionidae, Phyllostomidae, and Emballonuridae), although $52 \%$ of the fatalities belonged to just two species, Davy's naked-backed bat (Pteronotus davyi; $40.2 \%$ ) and the ghost-faced bat (Mormoops megalophylla; $11.9 \%$ ), both of the family Mormoopidae. These two species are particularly abundant in the area studied and form colonies with thousands of individuals in caves (García-Grajales and Silva 2012). Both are aerial-hawking and relatively fast-flying bats (Bateman and Vaughan 1974; Adams 1989). Also, unlike those species killed most frequently in Holarctic regions of North America, these species do not tend to roost in trees. Ninety-seven percent of bat fatalities found at wind turbines are resident species. This differs considerably from the USA, Canada, and parts of northern Europe, suggesting that wind turbines are equally dangerous to resident cave bats assumed to be non-migratory as to migratory tree-roosting species. The common theme is rather that the most frequently killed species are adapted to flight and echolocation in the open air (e.g., bats that have a relatively high wing loading). 


\subsubsection{Europe}

Rydell et al. (2010a) synthesized data from 41 sites in 5 countries in northwestern Europe and found that the Black Forest region in Germany $(n=10)$ had the highest annual fatality rates, averaging 10.5 bats killed/MW. Some regions in Germany had relatively low estimated annual fatality rates, averaging around 1.1-1.2 bats/ MW (Rydell et al. 2010a), yet some of these studies did not control for carcass removal and searcher efficiency. The single comprehensive study that covered most parts of Germany did take the aforementioned field biases into account when estimating annual fatality rates of $10-12$ bats per wind turbines, translating to 6-8 bats per MW produced (Korner-Nievergelt et al. 2013). Studies from mostly agricultural areas of Austria $(n=3)$, Switzerland $(n=3)$, and England $(n=1)$ yielded mean annual fatalities rates of 2.5, 5.3, and 0.6 bats killed/MW, respectively (Rydell et al. 2010a). In France, some particularly dangerous sites are located near water along the river Rhone in the east (Dubourg-Savage et al. 2011) and on the Atlantic coast in the west (Rydell et al. 2010a). In Spain, bat fatalities from 56 wind facilities ranged from 0.00 to 0.80 bats/MW per year (Camina 2012), but most studies did not correct for scavenger removal and searcher biases and therefore underestimate fatalities. In Portugal, annual fatality rates at 28 facilities ranged from 0.07 to $11.0 / \mathrm{MW}$ (L. Rodrigues, Instituto da Conservação da Natureza e das Florestas, unpublished data). Generally, data from Europe are inconsistently collected, rendering comparisons and generalizations across countries difficult. Nevertheless, it is clear that bats are frequently killed at wind turbines throughout the continent, with some facilities experiencing considerably higher fatality rates relative to others.

Members of EUROBATS recently synthesized data from several countries and reported 6429 documented bat kills of 27 species collected at wind facilities in Europe from 2003 to 2014 (EUROBATS 2014), but some studies used to derive estimates of fatality rates did not incorporate field bias or area corrections. The species of bats found most frequently at wind facilities across northern Europe were the common pipistrelle, common noctule (Nyctalus noctula), Nathusius' pipistrelle (Pipistrellus nathusii), and Leisler's bat (Nyctalus leisleri). In Germany, nearly $70 \%$ of recorded deaths represent the latter three species and the particolored bat (Vespertilio murinus), all of which are long-distance migrants (Hutterer et al. 2005). Owing to its central geographical location on the European continent, Germany appears to provide ecological stepping stones for many longdistance bat migrants from northeastern populations (Steffens et al. 2004; Voigt et al. 2012). However, resident species or short-distance migrants, including common pipistrelle and northern bats (Eptesicus nilssonii), also are frequently killed in northern Europe (Rydell et al. 2010a). The majority (>90\%) of bats killed at wind turbines in southern Europe belong to the various pipistrelle and noctule species: common pipistrelle, Nathusius' pipistrelle, soprano pipistrelle (Pipistrellus 
pygmaeus), Kuhl's pipistrelle (Pipistrellus kuhlii), and Savi's pipistrelles (Hypsugo savii) and the common noctule, giant noctule (Nyctalus lasiopterus) and Leisler's bat (Nyctalus leisleri). Some of these are long-distance migrants (e.g., Nathusius' pipistrelle and common noctule) that often roost in tree holes, while others are resident and usually house-living species that do not migrate long distances (e.g., Kuhl's pipistrelle and Savi's pipistrelle). Rare species, such as the barbastelle (Barbastella barbastellus) and the Myotis and Plecotus spp., also are killed occasionally, but in smaller numbers. Thus, bats killed at wind turbines in southern Europe generally belong to the same genera as those in northern Europe (Pipistrellus and Nyctalus spp.), but include several non-migratory species such as Kuhl's and Savi's pipistrelles.

\subsubsection{Africa}

Little work has been done on wind energy facilities in Africa, and prior to 2012, no studies had been published from the continent. During a pilot study at a single turbine located in the Eastern Cape of South Africa, Doty and Martin (2012) found 18 carcasses of 2 species of bats - the Cape serotine (Neoromicia capensis) and Egyptian free-tailed bat (Tadarida aegyptiaca). No estimates of fatality rates were provided, likely because of small sample size of recovered carcasses and no bat carcasses were used during field bias trials. In the Western Cape of South Africa, Aronson et al. (2013) reported only one carcass of a Cape serotine. These studies confirm at least some species of bats are vulnerable to wind turbine mortality in South Africa, which could have implications for ecosystem function and conservation of bats in this region.

\subsubsection{New Zealand and Australia}

In Australia, Hall and Richards (1972) were the first to report bat fatalities at a wind facility in the world, and 22 white-striped free-tailed bats (Tadarida australis) were found over a 4-year period. Little work had been done in the region since this pioneering discovery, until Hull and Cawthen (2012) surveyed two wind facilities in Tasmania, where they recorded 54 bat fatalities from two species, Gould's wattled bats (Chalinolobus gouldii) and an unknown Vespadelus sp. More recently, Bennett (2012) found white-striped free-tailed bats at two turbines located in Victoria. While no estimates of fatality rates were provided for these studies, they indicate that some species of bats are at risk of wind turbine mortality in this part of the world. 


\subsubsection{South America, Central America, and the Caribbean}

Few studies have been done in Latin American regions on bat fatalities caused by wind turbines. Puerto Rico hosts 13 species of bats of five families. Five of these 13 species belong to the family Phyllostomidae, which feed on fruits and nectar and forage in the understory and canopy (Gannon et al. 2005). It was originally speculated that these species would be at low risk for mortality caused by wind turbines based on their life histories and foraging patterns. Species in the family Molossidae also occur in Puerto Rico, and conversely, these species have been considered to be at higher risk to turbine collisions because they fly high in open spaces. Species from both families of bats have been detected during preconstruction surveys in areas where wind facilities were proposed. Twenty months of ongoing post-construction surveys in Puerto Rico revealed 30 carcasses from 11 of the 13 species, for a corrected mortality rate of about 10 bats/turbine /year (Rodríguez-Durán, Universidad Interamericana, unpublished data). Aside from the expected mortality of species in the family Molossidae, it was surprising that fruit and nectar feeding species of phyllostomids were followed in number of fatalities given their flight and foraging patterns. One important hazard for bats in this region relates to their use of hot caves as roosts (Rodríguez-Durán 2009; Ladle et al. 2012). Although little studied, these systems may be ubiquitous throughout parts of México, Panamá, Colombia, Venezuela, Brazil, and the Greater Antilles. Phyllostomids and mormoopids (family Mormoopidae) form large aggregations in hot caves and commute to foraging areas flying long distances at high altitude. This reliance on hot caves may place them at risk from wind facilities located near their feeding sites or along their commuting routes.

\subsubsection{Asia}

On the island of Taiwan off the Chinese mainland, wind facilities have been established along the western coastline, predominantly in former mangrove wetlands. Bat fatalities have been recorded at three of these facilities (C.H. Chou, Endemic Species Research Institute, unpublished data). Carcass searches and acoustic monitoring indicated regular feeding activity of bats near turbines in summer, and 51 dead bats were found. However, the study is ongoing and no field bias correction experiments have been conducted yet, so corrected fatality estimates are not available. The Japanese pipistrelle (Pipistrellus abramus), which is a non-migratory open-air foraging bat, was killed most frequently $(n=39)$. Six other species have also been found killed, although in smaller numbers (1-4 individuals for each species), namely Horikawa's brown bat (Eptesicus serotinus horikawai), common house bat (Scotophilus kuhlii), Chinese noctule (Nyctalus plancyi velutinus), Taiwanese golden bat (Myotis formosus flavus), a recently described mouse-eared bat (Myotis secundus), and Japanese long-fingered bat (Miniopterus fuliginosus). 
Three other species have been observed foraging around the turbines, but have not yet been found during carcass searches. These species are the yellow-necked sprite (Arielulus torquatus), Taiwanese tube-nosed bat (Murina puta), and East Asian free-tailed bat (Tadarida insignis). Several of these species (e.g., yellownecked sprite, Taiwanese golden bat, Taiwanese tube-nosed bat, Chinese noctule, Horikawa's brown bat, and M. secundus) are all island endemics, some of which occur in sparse and probably small and vulnerable populations. Nevertheless, the pattern conforms to that of most regions around the world, since the mortality predominantly (but not exclusively) affects species that feed in the open air (C.H. Chou, Endemic Species Research Institute unpublished data).

\subsubsection{Conclusions}

Bats are killed at wind turbines worldwide, and those fatalities are not restricted to migratory species at high latitudes, as previously suggested (e.g., Kunz et al. 2007a; Arnett et al. 2008). Hence, the bias toward tree-roosting migrants observed in North America and to some extent also in northern Europe is not consistent elsewhere. An emerging hypothesis is that bats that regularly move and feed in less cluttered and more open air-space are most vulnerable to collisions with wind turbines, regardless of continent, habitat, migratory patterns, and roost preferences. The species most often killed at wind turbines throughout Europe belong to aerial-hawking and relatively fast-flying, open-air species, and this is consistent with the pattern found in North America and Mexico. However, other species, including gleaning insectivores and even fruit feeders, also are killed occasionally. The vulnerability of tropical bat faunas is a potentially serious problem that must be addressed immediately and preferably before extensive wind facilities are planned and constructed.

While fatalities of endangered species like the Indiana bat are important from a legal perspective, they currently appear to be biologically irrelevant in comparison with those for hoary and eastern red bats, for example. However, fatalities of listed species worldwide may become increasingly important as wind energy development expands.

The paucity of studies in most regions of the world is alarming, particularly in Mexico, Central and South America, the Caribbean, Africa, New Zealand, and Australia. Notably, we could not find information on bat fatalities at wind facilities from mainland Asia, but the data from Taiwan indicate that the bat fauna of eastern Asia may be highly vulnerable at wind turbines. Turbine fatalities may be a serious threat to bats in, for example, China where wind energy development is substantial (Global Wind Energy Council, http://www.gwec.net/global-figures/graphs/\#). This situation is further complicated by the fact that in most countries information gathered is sequestered either by wind energy companies or government agencies and not made readily available. The importance of having access to this information cannot be overstated for all regions of the world. 


\subsection{Patterns of Bat Fatality}

\subsubsection{Temporal Patterns}

In the temperate Northern Hemisphere, most bat fatalities occur during late summer and early autumn. In the USA, fatalities peak in mid-July through early September in most parts of the country (Johnson 2005; Arnett et al. 2008; Baerwald and Barclay 2011; Arnett and Baerwald 2013). Studies from Europe demonstrate a similar pattern (e.g., in Germany, where most (about $90 \%$ ) bat fatalities at wind turbines occur between mid-July and the end of September; Brinkmann et al. 2011; Lehnert et al. 2014). Some studies from northern Europe and North America demonstrate smaller peaks of fatalities during spring (Arnett et al. 2008; Rydell et al. 2010a). In Greece and on the Iberian Peninsula of Spain and Portugal, the pattern is similar, with most $(>90 \%)$ fatalities in late summer (Georgiakakis et al. 2012; Camina 2012; Amorim et al. 2012), but in some places, particularly at high elevation sites, fatalities occur from May to October and without any obvious concentration in the late summer period (DubourgSavage et al. 2011; Camina 2012). Such consistent temporal patterns of fatality are helpful when predicting high-risk periods and applying some mitigation measures such as raising turbine cut-in speed (Arnett et al. 2011, Baerwald et al. 2009). Hull and Cawthen (2012) noted that fatalities predominantly occurred in autumn in Tasmania, where the climate is temperate. However, in the tropical Isthmus of Tehuantepec in Mexico, while $46 \%$ of bat fatalities were found in the summer rainy season, no clear pattern in bat deaths associated with any season emerged.

In summary, while there are clear temporal patterns and a distinct late summer fatality peak in high-latitude temperate regions (north Europe and North America), the pattern becomes less obvious in warmer climates at lower temperate latitudes (south Europe) and temporal patterns may dissipate entirely in tropical regions (e.g., southern Mexico).

\subsubsection{Spatial Patterns}

Arnett and Baerwald (2013) noted that the spatial context of bat kills, both among turbines within a facility and among different facilities, could be useful for developing mitigation strategies. They hypothesized that if, for example, kills were concentrated at specific turbines, then curtailment, removal, or relocating that turbine may reduce bat deaths. However, if fatalities are broadly distributed, then facilitywide mitigation strategies would be necessary (Arnett et al. 2008). Thus far, studies worldwide have failed to detect specific turbines responsible for most fatalities at any given facility.

Other patterns at scales beyond individual turbines have been reported that may assist with assessing risk. Baerwald and Barclay (2011) found no differences in 
fatalities on the east vs. west side of a facility in southern Alberta, but the fatality rate was higher at the north end. Baerwald and Barclay (2011) hypothesized that because fall migrations are from north to south, higher fatality rates could be expected at the more northerly turbines first encountered by migrating bats. At a landscape scale, Baerwald and Barclay (2009) found both higher activity and fatality rates of bats at wind facilities near the foothills of the Rocky Mountains as compared to eastward prairie grasslands. They speculated that turbine proximity to stopover and roost sites in foothills habitat significantly increased fatality rates assuming that geographical landmarks are used for navigating migration routes and that bats judge nightly travel distances between suitable diurnal roosting sites.

\subsubsection{Habitat Relationships}

Relationships between bat fatalities and habitat or topographic characteristics may be useful for developing mitigation strategies (e.g., to avoid placing turbines near places where many bats move or forage, such as near open water sources, wetlands, or known roosts; Arnett et al. 2008; Arnett and Baerwald 2013; Rydell et al. 2010a). Johnson et al. (2004) did not find a significant relationship between the number of bat fatalities and any of the 10 cover types within $100 \mathrm{~m}$ of turbines at facilities in Minnesota or any relationship between fatalities and distance to nearest wetland or woodlot. In assessing the type of vegetation present in areas where the fatalities were found in wind facilities in the Isthmus of Tehuantepec, 79.6\% occurred in agricultural areas. In Oklahoma in 2004, Piorkowski and O'Connell (2010) found that turbines in eroded ravine topography accounted for higher fatality rates than those in areas of low topographic relief and reported some evidence that turbines in mixed cedar/pasture habitats killed more bats than those in cropland and prairie habitats. However, these patterns were not repeated in 2005 or for both years of the study when combined, and Piorkowski and O'Connell (2010) speculated that bats may have exhibited different habitat use patterns in different years or they did not measure factors better explaining annual differences they observed. Interestingly, Grodsky (2010) found that bat fatalities were actually lower near the Horicon Marsh in Wisconsin. Hull and Cawthen (2012) found no relationships between bat fatalities and proximity of turbines to the coast or vegetation. Hence, correlating high-risk locations with particular habitat types or topographic patterns has proven difficult and inconsistent.

Analyses of fatalities reported from Spain and Portugal, where most wind facilities are located on top of hills and mountains, suggest that the most significant environmental predictor of fatality rate is proximity to steep slopes with bare rock and no vegetation. Bare rock is warmed by the sun and radiates heat during the night, which likely facilities insect activity over the rocks (Ancilotto et al. 2014), possibly explaining higher fatality at sites near steep, rocky slopes. Alternatively, rocks on tops of hills and mountains might provide suitable roosts. 
Piorkowski and O'Connell (2010) documented the first evidence of fatality of Mexican free-tailed bats at a North American wind facility that could be attributed to the site's proximity $(\sim 15 \mathrm{~km})$ to a large maternity colony. In Wisconsin, Grodsky (2010) found no relationship between distances of turbines from a large hibernaculum (Neda Mine), but in this case, hibernating bats did not belong to the species most vulnerable to wind turbine mortality (see above). Georgiakakis et al. (2012) reported that the most frequently killed species at wind facilities in Greece exhibited different spatial patterns of fatality, speculating that this resulted from some turbines being located closer to roosts and/or commuting corridors. It may not be enough to consider the proximity of a facility to a maternity or hibernation site, but rather where it is located relative to feeding grounds or movement corridors (Arnett and Baerwald 2013). We are not aware of other studies demonstrating similar relationships or patterns with large maternity or winter roosts.

\subsubsection{Climate and Weather Variables}

Arnett (2005) was first to employ daily carcass searches and relate them to weather variables, discovering that most bats were killed on low-wind nights when power production appeared insubstantial. Based on this approach, Arnett et al. (2008) estimated that $82-85 \%$ of bat fatalities at two facilities in the eastern USA occurred on nights with median nightly wind speeds of $<6 \mathrm{~m} / \mathrm{s}$. Since this pivotal discovery, studies worldwide document that most bat fatalities occur during low-wind periods. In the USA, for example, Jain et al. (2011) found that maximum wind speeds when bat collisions likely occurred ranged from 2.4 to $5.3 \mathrm{~m} / \mathrm{s}$. Korner-Nievergelt et al. (2013) found that maximum collision rates of bats occurred at wind speeds between 3.5 and $5.7 \mathrm{~m} / \mathrm{s}$. Several other studies from Europe demonstrate a similar pattern (e.g., Amorim et al. 2012). Indeed, this consistency suggesting bat fatality is highest during lower wind speeds greatly assists predicting high-risk periods during which to apply operational mitigation.

Fatalities appear to increase as ambient temperature rises, a relationship observed in North America (e.g., Grodsky 2010; Young et al. 2011) and Europe (e.g., in Portugal; Amorim et al. 2012). Amorim et al. (2012) also found that bat fatalities increased with decreasing relative humidity. The effect of high temperature on fatality rate seems to apply both on the broader regional and climatic scales and according to daily changes in the weather (Dubourg-Savage et al. 2011 and unpublished data). Hence, at least in southern Europe, high fatality rates at wind turbines are most likely in warm and dry geographic areas (Mediterranean and low elevation) and also in warm weather (most common in late summer). In the end, this suggests that fatalities may be correlated with periods of high insect activity, which generally is most likely to occur under warm and dry conditions (Heinrich 1993). 
Bat fatalities also have been correlated with other climatic factors that could assist with predicting high-risk periods. Baerwald and Barclay (2011) reported that species-specific fatalities were affected by greater moon illumination. They also observed that falling barometric pressure and the number of deaths were correlated and that whereas fatalities of silver-haired bats increased with increased activity of this species, moon illumination, and south-easterly winds, hoary bat mortality increased most significantly with falling barometric pressure. Interestingly, neither hoary bat activity nor fatality was influenced by any measured variables other than falling barometric pressure (Baerwald and Barclay 2011). Again, this could result from decreasing barometric pressure that triggers insect flight activity and therefore may motivate foraging efforts among bats by indicating a potential increase in food availability (Wellington 2011).

\subsection{Offshore Wind Facilities}

Potential impacts of offshore wind-energy development on bats are poorly understood, although observations in Europe and anecdotal accounts of bats occurring offshore suggest that impacts may occur. Bats are known to regularly migrate across the Baltic and North Seas and visit offshore facilities (Hutterer et al. 2005; Boshamer and Bekker 2008; Ahlén et al. 2009; Poerink et al. 2013; Rydell et al. 2014). Ahlén et al. (2009) recorded 11 species of bats flying and feeding over the sea up to $14 \mathrm{~km}$ from the shore. In spring and late summer, migrating bats are found along coastlines of the Baltic Sea and southeastern North Sea in northern Europe, including all offshore islands where observations have been made (Rydell et al. 2014). This suggests bats, including Nathusius' pipistrelles, soprano pipistrelles, and common noctules, migrate on a broad front across the Baltic Sea and along its coasts, using small islands for stopovers. Researchers in North America also have reported activity of bats in both near and offshore habitats, suggesting impacts are highly probable at facilities located in such places. Cryan and Brown (2007) discovered longitudinal movement by hoary bats from inland summer ranges to coastal regions during autumn and winter and suggested that coastal regions with non-freezing temperatures may be important wintering areas for hoary bats. Off the coast of Maryland, Johnson et al. (2011) recorded five species of bats, including eastern red bats, big brown bats (Eptesicus fuscus), hoary bats, tri-colored bats (Perimyotis subflavus), and silver-haired bats, on a barrier island and concluded these species used this island during migration, which could have implications for wind energy development near and offshore.

It seems likely that near and offshore wind facilities also will kill bats, but it is difficult or impossible to find bat fatalities at sea and no attempts to assess offshore turbine bat fatality have been made to date. Arnett and Baerwald (2013) suggested that impacts of the first several offshore wind-energy facilities proposed and built in North America, including those on inland waters such as the Great Lakes, be evaluated extensively both for fatalities and displacement effects. 
They also suggested that a method for predicting fatalities at existing and planned wind facilities offshore will be required to understand impacts and develop mitigation strategies, because finding and retrieving dead birds and bats from water bodies will be a considerable challenge (Arnett et al. 2007; Arnett 2012).

\subsection{Estimating Risk}

Kunz et al. (2007b) found a positive correlation between post-construction bat activity and fatality from carcass searches conducted simultaneously. However, Kunz et al. (2007b) warned of several limitations of their analysis and noted that it was unclear whether pre-construction call rates could predict risk and level of post-construction fatality rates. When comparing 5 sites with fatality and activity data, and tall turbines (towers $65 \mathrm{~m}$ ), Baerwald and Barclay (2009) found a significant positive relationship between post-construction activity and fatality at 5 wind facilities in Alberta. Amorim et al. (2012) and Korner-Nievergelt et al. (2013) also found increasing number of bat fatalities with increasing acoustic bat activity at facilities in Portugal and Germany, respectively. These studies correlating post-construction bat activity with fatality suggest that it may be possible to use indices of pre-construction bat activity to predict future fatality and, thus, risk and need for mitigation. However, while numerous studies have documented pre-construction activity of bats with hopes of inferring risk of collision mortality, these studies have yet to link with post-construction fatality data gathered from carcass searches. Hein et al. (2013) were the first to correlate pre-construction acoustic activity with post-construction fatalities from 12 paired study sites in the USA and found that no statistically significant relationship existed between bat fatalities/MW and bat passes/detector night and only a small portion of the variation in fatalities was explained by activity. Thus, Hein et al. (2013) concluded that prediction of risk prior to construction of a wind facility is highly variable and imprecise and acoustic data may not necessarily predict bat fatality in any reliable way. One explanation as to why correlations between pre-construction measurements of bat activity with similar measurements made post-construction or fatality estimates are weak could be that bats are attracted to the turbines once they are built and sites are used differently by at least some species (open-air bats) afterward (Horn et al. 2008; Kunz et al. 2007b; Arnett et al. 2008; Cryan et al. 2014).

Theoretical estimations of exposure risk of bats to collisions with turbines based on models may also improve our understanding of factors influencing fatality and the context of fatalities. Species distribution models developed in Italy suggest that $41 \%$ of the region offers suitable foraging habitat for 2 species of bats vulnerable to wind turbines, Leisler's bat and the common pipistrelle, and these same areas encompass over $50 \%$ of existing or planned wind farms (Roscioni et al. 2013). The authors believe fatality risk for these species is increased by the common proximity to forest edges, but this contradicts other findings from southern Europe, suggesting the opposite relationship (Dubourg-Savage et al. 2011). 
Roscioni et al. (2014) further investigated habitat connectivity as a surrogate for assessing risks of wind facilities to bat migration and commuting in Italy. Using species distribution models, they found that most corridors used by bats were concentrated in an area where existing (54\%) and planned (72\%) wind facilities would interfere with important corridors connecting the western and the eastern parts of the region. In Portugal, mortality risk models indicated wind farms located in humid areas with mild temperatures and within $600 \mathrm{~m}$ of steep slopes had higher probabilities of mortality (Santos et al. 2013). They also demonstrated that high mortality risk areas overlapped greatly with the potential distribution of Leisler's bat in Portugal, suggesting that populations of this species may be at high risk to turbine fatalities (Santos et al. 2013). They also found that a large extent of the area predicted to be high risk for mortality overlapped with sites highly suitable for wind farm construction.

\subsection{Cumulative Impacts}

Estimates of fatalities, and thus any estimate of cumulative fatalities, are conditioned by field methodology for each study (e.g., search interval) and how each study did or did not account for sources of field sampling bias when calculating fatality rate estimates. Arnett and Baerwald (2013) synthesized information from 122 post-construction fatality studies (2000-2011) from 73 regional facilities in the USA and Canada and developed a regional weighted mean estimate of cumulative bat fatalities for the USA and Canada. Assuming fatality rates were (1) representative of all regional sites and (2) consistent from year to year without behavioral modification or mitigation, Arnett and Baerwald (2013) estimated cumulative bat fatalities in the USA and Canada ranged from 0.8 to 1.7 million over a 12-year period from 2000 to 2011 . This estimate was projected to increase by $0.2-0.4$ million bats in 2012 based on the assumptions and installed wind power capacity. Smallwood (2013) estimated 888,000 bats killed/year at wind facilities in the USA, while Hayes (2013) concluded that over 600,000 bats may have been killed by wind turbines in 2012 alone. However, neither of these estimates used all data available at the time they were published, nor did they weight their estimates by regionally collected data and installed wind energy capacity as Arnett and Baerwald (2013) did; the latter approach likely provides a more conservative and accurate estimate based on the studies and installed capacity from each region.

When controlling for field biases, an estimated 10-12 bats are killed annually at each wind turbine in Germany, if no mitigation measures have been implemented (Brinkmann et al. 2011). Assuming these numbers are representative of all types of wind turbines for all of Germany, it has been suggested that more than 200,000 bats were killed at onshore wind turbines in Germany, assuming no behavioral modification or mitigation measures were practiced (Voigt et al. 2015a). Over the past ten years of wind energy development, it is estimated that 
more than two million bats may have been killed by wind turbines in Germany, based on the reported large-scale development of wind turbines in that country (Berkhout et al. 2013; Voigt et al. 2015a).

Importantly, the context of wind turbine fatalities remains poorly understood, in part because little population data exist for most species of bats (O'Shea et al. 2003) and this hinders understanding population-level impacts, as well as effectiveness of mitigation measures. Population estimates for most species of bats around the world are lacking, and some bat populations are suspected or known to be in decline (e.g., Frick et al. 2010; Hutson et al. 2001; Ingersoll et al. 2013). Other populations, such as hibernating species in Europe, appear to be increasing ( 9 of 16 species examined by Van der Meij et al. (2014) increased at their hibernation sites from 1993 to 2011), but these species are not largely affected by wind turbines. In addition to natural and other forms of anthropogenic-induced mortality, wind turbine mortality further compounds population declines for many species of bats and warrants mitigation.

\subsection{Mitigating Bat Mortality}

As reported previously, most bat fatalities occur during relatively low-wind conditions over a relatively short period of time in late summer (Arnett et al. 2008) and operational adjustments under these conditions and during this time could reduce impacts on bats (Arnett 2005; Arnett et al. 2008; Kunz et al. 2007a). Behr and von Helversen (2006) were the first to examine operational mitigation in Germany, documenting around $50 \%$ fewer bats killed at turbines having their cut-in speed (wind speed at which turbines begin producing electricity into the power grid) raised above the set manufacture's cut-in speed of $4.0 \mathrm{~m} / \mathrm{s}$. In the synthesis of operational mitigation studies in the USA and Canada, Arnett et al. (2013a) reported that most studies documented at least a $50 \%$ reduction in bat fatalities when turbine cutin speed was increased by $1.5 \mathrm{~m} / \mathrm{s}$ above the manufacturer's cut-in speed, with up to a $93 \%$ reduction in bat fatalities in one study (Arnett et al. 2011). Baerwald et al. (2009) demonstrated beneficial reductions $(\sim 6 \%)$ with a low-speed idling approach. Young et al. (2011) discovered that feathering turbine blades (pitched $90^{\circ}$ and parallel to the wind) at or below the manufacturer's cut-in speed resulted in up to $72 \%$ fewer bats killed when turbines produced no electricity into the power grid. Arnett et al. (2013a) noted that studies failing to demonstrate statistically significant effects could be explained by lack of treatments being implemented during the study (i.e., winds were either too low or high to enable comparison of treatments). In Portugal, a mitigation study found that estimated mortality at turbine with raised cut-in speed was 0.3 bats/turbine compared to 1.6 bats/turbine at turbines operating normally, which resulted in a $78.5 \%$ reduction in bat fatalities assuming all turbines at the facilities had raised cut-in speed (LEA 2010).

More recently, situation-dependent operation protocols, so-called algorithms, were developed for the operation of wind turbines. These algorithms consider a 
number of parameters such as ambient temperature, wind speed, season, and time of day as well as recorded bat activities for defining a set of operation rules for wind turbines (Korner-Nievergelt et al. 2013). However, these algorithms have been formulated for a single type of turbine and for a limited number of sites. Thus, the suggested algorithms may be unsuitable for other places with varied geographical and topographic characteristics, bat communities, and turbine types (Voigt et al. 2015a).

Few studies have disclosed actual power loss and economic costs of operational mitigation, but those that have suggest that $<1 \%$ of total annual output would be lost if operational mitigation was employed during high-risk periods for bat fatalities. While costs of lost power due to mitigation can be factored into the economics, financing, and power purchase agreements of new projects, altering turbine operations even on a limited-term basis potentially poses difficulties on existing projects. Although curtailment is relatively straightforward to implement on large modern turbines, for older models and for small to medium energy-generating turbines, there often is no way to remotely control or change cut-in speed; some turbines would require a technician to physically change turbine operating systems (which is not feasible). However, raising cut-in speed or altering blade angles to reduce rotor speed (termed "low-speed idling" by Baerwald et al. 2009) where blades are near motionless in low wind speeds remain the only proven solutions to mitigating bat kills at wind facilities. The fact that it may be difficult to apply these mitigation techniques to some old turbines should not compromise its use on contemporary turbines.

Other approaches to mitigating bat fatalities have been suggested, including projecting electromagnetic signals from small, portable radar units (Nicholls and Racey 2009) and ultrasonic broadcasts (Arnett et al. 2013b). However, the former approach has not been tested at large, utility-scale facilities, and none are yet being implemented broadly at wind energy facilities. Future studies of any mitigation approach must demonstrate greater or equal effectiveness to operational adjustments and also be cost-competitive with different operational strategies for mitigation.

\subsection{Conservation Policy}

In this section, we discuss a few selected issues regarding policy and regulation of wind facilities as they relate to wildlife impacts and successful integration of science, policy, and management to improve siting that minimizes risk to wildlife, including bats. This discussion is by no means exhaustive or comprehensive, but rather offers examples of policy issues from different regions of the world.

In the USA, the federal government's role in regulating wind power development is limited to projects occurring on federal lands, impacting federal trust species, or projects that have some form of federal involvement (e.g., interconnect with a federal transmission line) or require federal permits. The primary federal 
regulatory framework for protecting wildlife from impacts from wind power includes three laws - the US Migratory Bird Treaty Act, the Bald and Golden Eagle Protection Act, and the Endangered Species Act (ESA; GAO 2005; NRC 2007). Because wind-energy development has primarily occurred on non-federal land, regulating such facilities is largely the responsibility of state and local governments (GAO 2005). The primary permitting jurisdiction for wind-energy facilities in many instances is a local planning commission, zoning board, city council, or county board of supervisors or commissioners, and typically, these local jurisdictional entities regulate wind projects under zoning ordinances and building codes (GAO 2005), often without the basic knowledge needed to make informed decisions. Additionally, each state may enforce its laws regarding wind energy and wildlife impacts or establish cooperative efforts to address impacts. The US Fish and Wildlife Service has voluntary guidelines designed to help wind energy project developers avoid and minimize impacts of land-based wind projects on wildlife and their habitats (U.S. Fish and Wildlife Service 2012). In the USA, most species of bats, including migratory tree-roosting species killed most frequently by turbines, are not protected under federal, state, or provincial laws (Arnett 2012; Cryan 2011). Documented presence or fatality of species listed as threatened or endangered under the ESA (e.g., Indiana bat) does not necessarily mandate monitoring or mitigation as one might expect; rather, all efforts are voluntary even in cases involving a listed species, although threat of prosecution under the ESA increases when operators fail to collaborate or develop a conservation and mitigation plan.

Until recently, an Environmental Impact Assessment (EIA) in Canada was required under the Canadian Environmental Assessment Act (CEAA) when a Federal Authority initiated a wind project, granted any form of financial assistance or land for the project, and/or performed a regulatory duty in relation to the project, such as issuing a permit or license. Given that the Canadian Federal Government provided financial incentives for wind energy from 2002 to 2011, EIAs of wind energy projects were generally mandatory. However, wind energy projects no longer require federal environmental assessments (Canadian Environmental Assessment Act 2012), but projects may still require an environmental assessment if requested by the province or territory. Bats fall under the jurisdiction of the individual provinces (ten) and territories (three). As such, there are no Canada-wide bat and wind-energy policies or regulations; each province or territory sets their own policy and/or regulation regarding bats and wind energy projects (e.g., Ontario Ministry of Natural Resources 2011; Government of Alberta 2013). The Ontario Ministry of Natural Resources set a mortality threshold of 10 bats/turbine/year, which if exceeded triggers operational mitigation across the wind facility from 15 July to 30 September for the duration of the project (Ontario Ministry of Natural Resources 2011). This mortality threshold was based on fatality rates of bats at wind energy projects in Ontario and across North America. Ontario's guidelines do not explicitly consider cumulative effects (i.e., operational mitigation is only triggered by project-specific fatality rates). In Alberta, the integration of data, including acoustic data, collected during both the pre- and postconstruction monitoring, helps guide the mitigation framework (Government of 
Alberta 2013). For example, if less than five migratory-bat passes/detector night are recorded during pre-construction acoustic monitoring, then the project is considered to be a potentially acceptable risk, but if greater than ten migratory-bat passes/detector night were recorded, the project is considered to have a potentially high risk of bat fatalities and will likely require operational mitigation (Government of Alberta 2013). Unlike Ontario's guidelines, Alberta's mitigation framework explicitly considers cumulative effects (i.e., the proximity and risk at wind energy projects in the area are considered when determining the need for operational mitigation). Given the wide-ranging movement patterns of migratory tree bats and the tendency for wind energy projects to be clustered, from a conservation perspective, a policy which considers cumulative effects is superior to one that does not (Arnett et al 2013c).

Development of wind facilities in Mexico is regulated by laws and norms that have been enacted to achieve sustainable development. The General Law of Ecological Balance and Environmental Protection (GLEBEP) and its regulations are the main legal instruments the Mexican government has to protect ecosystems (www.semarnat.gob.mx). According to the GLEBEP, for a wind facility to be built, it is necessary to develop an EIA to determine the environmental feasibility of the project. The environmental authority has developed methodological guidelines for productive sectors to perform studies that meet the minimum information necessary for evaluation. In this case, the wind facilities are included in the energy sector, which includes, among others, hydroelectric, thermal, combined cycle plants, transmission lines, dams, and electrical substations. The first wind facility EIA (2000-2004) was completed with evaluations similar to those used for any other infrastructure (e.g., hydroelectric, thermoelectric, etc.) and was therefore not focused on impacts associated with wind facilities; collisions of birds and bats are not considered in the EIA. Thus, mitigation to reduce these impacts was not required by any regulatory authority at the first wind facilities in Mexico. Recently, the Mexican government has begun considering negative impacts on birds and bats and has incorporated measures including an annual monitoring program in these taxa during the entire cycle of wind energy projects. While there is no regulatory framework specifically for protection or conservation of bats in Mexico, there is an official standard that includes listings of flora and fauna found in risk categories similar to the Red List of the International Union for Conservation of Nature. The NOM-059-SEMARNAT-2010 (SEMARNAT 2010) includes the three categories of risk in order from most to least critical: in danger of extinction, threatened, and under special protection. The inclusion of species in each of these three categories is in accordance with technical and scientific criteria (SEMARNAT 2010). The NOM-059-SEMARNAT-2010 includes 38 species of bats, 19 of which warranted special protection. To date, however, only four species included in the NOM-059 have been found killed at wind facilities, and none of the species killed most frequently by turbines in Mexico are included in the NOM59 given their abundance and wide distribution (Ceballos and Arroyo-Cabrales 2012; Ceballos et al. 2005). Apart from these legal instruments, there are no other legal mechanisms in Mexico to protect Mexican bats per se. 
In the European Union, all species of bats, regardless of numbers, are strictly protected by law and it is illegal to deliberately kill or harm bats irrespective of any population effects. "Deliberately" means in this case that the actor is aware that activity may have an effect but still carries out the activity. The EIA Directive 85/337/EEC (amended to Council Directive 97/11/EC in 2011) legally requires an assessment to be carried out for all wind facilities with 5 or more turbines, or which are over $5 \mathrm{MW}$ capacity. In addition, member states must restore or maintain their bat populations in favorable conservation status (Council Directive 92/43/EEC). All members of the EU have translated these directives into their domestic legislation which in theory should provide high levels of protection and a consistent way of handling the issue, based on the EUROBATS guidelines (Rodrigues et al. 2015). However, while bat issues are taken very seriously in some countries, this is not true in others. In the UK and Republic of Ireland, it is an offense to deliberately or recklessly kill or injure a bat or to deliberately disturb bats in a way that would significantly affect their local distribution or abundance, and detailed guidance is in place about the requirements for EIA.

The EUROBATS guidance (Rodrigues et al. 2015) proposes that turbines should not be placed closer than $200 \mathrm{~m}$ to woodland, whereas the current recommendations for the UK are that the blade tips should be at least $50 \mathrm{~m}$ from woodland or hedgerows. It is argued that a smaller buffer size is acceptable because the activity of bats found in the UK tends to decline rapidly with increasing distance from linear landscape features and woodlands (Natural England 2014). It is officially acknowledged that risk assessments for bats in the UK and Republic of Ireland are hampered by a lack of evidence in crucial areas (Bat Conservation Ireland 2012; Natural England 2014). Not only are collision rates unknown, but population estimates, and therefore inferences about the impact of turbine collisions on population viability, are uncertain. Standardized post-construction monitoring, including acoustic and carcass surveys, is recommended for sites identified as "high risk" (Bat Conservation Ireland 2012; Natural England 2014).

In reality, little post-construction monitoring occurs. This is at least partly because responsibility for requiring and enforcing survey conditions lies with local planning authorities, which are reluctant to impose conditions which may be open to legal challenge. A particular difficulty is that while generic guidance on survey designs is available, there is no standardized methodology and so it is extremely difficult to judge whether a particular level of bat activity would place a site as being in a "high risk" category: This point has already been raised at a legal review. Further, there has been no assessment of the relationship between pre-construction and post-construction acoustic surveys (or collision risk). It is therefore unclear how data collected pre-construction can be used to predict post-construction risk, particularly given evidence from the USA demonstrating a poor relationship between pre-construction activity surveys and bat fatalities (Hein et al. 2013). A final difficulty for Local Authorities is that the legal basis of bat protection relates to the conservation status of local populations (except in Scotland, where recklessly killing a bat is also an offense). Given that local population sizes are very poorly characterized, it is unclear how mitigation (such as 
raising turbine cut-in speed) could be enforced on the basis of reduced bat activity or bat fatalities.

In Sweden, there were no national guidelines until 2011 (Rydell et al. 2012), and more than ten years after the first turbines were built. Hence, many wind turbines in Sweden were constructed in poor locations with respect to bats, such as along the coast, and with operation permitted without any mitigation measures. After 2011, however, the Swedish Environmental Protection Agency concentrated resources to achieve national acceptance for the guidelines among decision makers, the industry and NGOs, and to implement them on all new project. In 2014, all proposed wind facilities are subject to a pre-construction survey and an evaluation regarding the risk to bats. In the Netherlands, all bats are species of annex II and/ or IV of the European Habitats Directive EIA, and risk assessment and evaluation under Flora and Fauna law (research on what species are present) and possibly Nature Conservation law (when EHD annex II species are present) are obligatory. When risk species are present and fatalities cannot be excluded, a permit for construction is needed under FF law and NC law, and information on fatalities needs to be established using protocols and a curtailment may be required (Boonman et al. 2013; Limpens 2013).

Mitigation studies have shown that bat fatalities can be reduced substantially (e.g., Baerwald et al. 2009; Arnett et al. 2011). Although curtailing turbines holds great promise, the problem is that developing thresholds-those values that trigger some action - to mitigate bat kills is difficult, especially when supporting data are limited or imperfect (Arnett et al. 2013c). In Germany, recent models accounting for multiple environmental variables that predict and reduce collision rate and further minimize loss of energy production offer promise for mitigating bat fatalities (Korner-Nievergelt et al. 2013). However, these algorithms and most other operation protocols still tolerate an arbitrary number of bat fatalities (currently two bat fatalities per wind turbine per year where these algorithms are used in Germany) (Voigt et al. 2015a); any such fatality trigger in Europe is seemingly in opposition to current law, given that European legislation does not allow deliberate killing of any bat, regardless of population effects. Additionally, with increasing numbers of wind turbines, fixed annual "per capita" (i.e., per wind turbine) mortality rates may not be acceptable in light of limited bat population sizes, and the acceptance of a reduced fatality rate may not necessarily be consistent with national and EU legislation (Voigt et al 2015a). Regulatory authorities in the US state of Pennsylvania and the Canadian province of Ontario set thresholds for initiating curtailment based on the annual mean number of bats killed per turbine (28 and 10 bat fatalities/turbine, respectively Arnett et al. 2013c). Arnett et al. (2013c) argued that this approach sets a dangerous precedent and has several flaws, none the least of which is the assumption that bat populations are currently stable and remain so. This approach also ignores expanding development of wind turbines that will likely yield increasing bat fatalities per population or region. Policy and management efforts to mitigate bat fatalities and conserve bat populations affected by wind turbines should be proactive and based on science rather than being reactive and arbitrary. 


\subsection{Future Directions}

Population data are generally lacking, and this not only impedes our understanding of actual impacts of wind turbines, but also impedes knowing the effectiveness of mitigation efforts. For example, we do not know whether raising turbine cut-in speed that might result in $50 \%$ fewer bat fatalities will mitigate population-level impacts or simply delay inevitable losses (Arnett and Baerwald 2013). The lack of population data also makes it difficult to set triggers for mitigation (i.e., number of bats killed per turbine or MW that requires mitigation; but see Arnett et al. 2013c). However, population data are not likely to be available for most bat species in the near future, and thus, wind operators should practice the precautionary principle and implement operational mitigation at sites where bat fatalities are high, or are predicted to be high, even in the absence of population data.

Several knowledge gaps remain that must be filled in the immediate future. Most notably, many regions of the world lack any publicly available monitoring information on the impacts of wind energy facilities on bats and other wildlife (e.g., China). We strongly encourage wind energy developers and governments to end this trend and gather needed data to inform siting and operating wind facilities around the world. In addition to population studies and basic monitoring data described above, some key research priorities germane to all regions of the world include:

1. Evaluating effectiveness of pre-construction bat activity surveys in predicting future fatalities at wind facilities.

2. Determining whether approaches such as temperature profiles in relation to weather types and seasons (and different regions) or habitat suitability modeling for bats can effectively predict high-risk sites and be used by planning authorities and industry to help situate wind turbines in areas where the potential for conflict with bats is minimized.

3. Evaluate methods for assessing the risk and minimizing and mitigating impacts posed by offshore wind turbines to bats (including approaches such as radar and collision sensors).

4. Investigate the extent of migratory activity worldwide, particularly offshore, by international collaboration using a range of techniques [stable isotopes (Voigt et al. 2012; Lehnert et al. 2014; Baerwald et al. 2014), population genetics, potentially GPS tracking, etc.]. Although difficult, it may be possible to gather and pool acoustic data of activity patterns established through automated real-time recorders in numerous wind energy facilities to evaluate spatial and temporal patterns.

5. Future operational mitigation experiments should be designed to determine which factors (e.g., habitat, insect occurrence, temperature, wind, humidity, moon illumination) or combination of factors (Weller and Baldwin 2012) will best improve predictability of bat fatalities, while minimizing economic costs. Alternative mitigation approaches to operational adjustments should be proven equally or more effective at reducing bat fatalities at operating wind facilities before being accepted as viable mitigation approaches. 
6. Detailed meta-analyses of existing data on cumulative fatality impacts and factors influencing fatalities are needed. It should be noted that data disclosure from many sites by some companies hinders such analyses.

We strongly encourage developers to follow guidelines (e.g., Kunz et al. 2007b; Rodrigues et al. 2015; Strickland et al. 2011; Bat Conservation Ireland 2012) consistently when implementing pre- and post-construction monitoring. Data should be placed into the public domain or preferably published in refereed journals. There are a number of policies, regulatory, and communication challenges we face in protecting bats while developing wind energy responsibly across the globe (Arnett 2012). Unless there is a federal, state, or provincial nexus, most research, siting, and mitigation efforts by wind energy developers and operating companies will be voluntary, likely without regard for cumulative effects. Sites that do trigger a regulatory nexus will usually be driven by endangered species issues (e.g., Indiana bats in the USA). It is apparent most local jurisdictional entities, regardless of country, lack experience in wildlife science, and unless they coordinate with their wildlife or natural resource agency specialists, concerns about bat fatalities may never be addressed in decision making for wind energy development. Another key issue is consistent application of regulations. The authors have encountered many situations where different individuals had varied interpretations of the same law or guidance policy, and this creates untenable situations, considerable uncertainty, consternation, and lack of trust among stakeholders that seems completely unnecessary and easily remedied (Arnett 2012).

We encourage continuing cooperation among all stakeholders, gathering needed information, avoiding construction in high-risk sites, considering cumulative effects, and implementing mitigation where needed even when no regulatory process is triggered (Arnett 2012; Arnett and Baerwald 2013). Wind energy developers should, however, be treated fairly and consistently to ensure proactive measures are implemented. Arnett (2012) noted that when some companies choose to cooperate, while others may not, unnecessary angst is generated and deters resolving wildlife impacts and other issues. Decision making must be based on the best available science. Also, consistent policy, accountability, effective siting and mitigation strategies, and a "level-playing field" for the industry (i.e., consistent requirements and incentives for all companies) are fundamental if we are to successfully develop wind energy that protects bats and other wildlife.

Acknowledgements We appreciate the invitation from C. Voigt and T. Kingston to prepare this chapter. Portuguese data were collected by AgriPro Ambiente, Bio3, Biota, Colmus, Ecomind, Ecosativa, Ecosfera, EDP, ENEOP2, EolFlor, LEA, Naturibérica, NOCTULA, Plecotus, PROCESL, Profico Ambiente, ProSistemas, STRIX, and Tecneira. We acknowledge C.-H. Chou at the Endemic Species Research Institute in Taiwan for letting us cite his important but yet unpublished data. This chapter was greatly enhanced by reviews from C. Hein, T. Kingston, H. Limpens, and 2 anonymous reviewers. We wish to dedicate this chapter to our friend Dr. Thomas Kunz for all of his wisdom, knowledge, and efforts in regard to wind energy impacts on bats. 
Open Access This chapter is distributed under the terms of the Creative Commons Attribution Noncommercial License, which permits any noncommercial use, distribution, and reproduction in any medium, provided the original author(s) and source are credited.

\section{References}

Adams JK (1989) Pteronotus davyii. Mamm Species 346:1-5

Ahlén I, Baagøe HJ, Bach L (2009) Behavior of Scandinavian bats and foraging at sea. J Mammal 90:1318-1323

Amorim F, Rebelo H, Rodrigues L (2012) Factors and mortality at a wind farm in the Mediterranean region. Acta Chirop 14:439-457

Ancilotto L, Rydell J, Nardone V, Russo D (2014) Coastal cliffs on islands as foraging habitat for bats. Acta Chirop 16:103-108

Arnett EB (2005) Relationships between bats in Pennsylvania and West Virginia: an assessment of bat fatality search protocols, patterns of fatality, and behavioral interactions with wind turbines. Bat conservation international, Austin, Texas, USA http://www.batsandwind.org/p df/postconpatbatfatal.pdf. Accessed 22 Dec 2014

Arnett EB (2012) Impacts of wind energy development on wildlife: challenges and opportunities for integrating science, management. In: Sands JP, DeMaso SJ, Brennan LA, Schnupp MJ (eds) Wildlife science: with management. Taylor and Francis, New York, pp 213-237

Arnett EB, Baerwald EF (2013) Impacts of wind energy development on bats: implications for conservation. In: Adams RA, Peterson SC (eds) Bat evolution, ecology, and conservation. Springer, New York, pp 435-456

Arnett EB, Inkley DB, Larkin RP, Manes S, Manville AM, Mason JR, Morrison ML, Strickland MD, Thresher R (2007) Impacts of wind energy facilities on wildlife and wildlife habitat. Wildl Soc Tech Rev 07-2 (The Wildlife Society, Bethesda, Maryland)

Arnett EB, Brown K, Erickson WP, Fiedler J, Henry TH, Johnson GD, Kerns J, Kolford RR, Nicholson CP, O'Connell T, Piorkowski M, Tankersley R Jr (2008) Patterns of fatality of bats at wind energy facilities in North America. J Wildl Manage 72:61-78

Arnett EB, Huso MMP, Schirmacher MR, Hayes JP (2011) Changing wind turbine reduces at wind facilities. Front Ecol Environ 9:209-214. doi:10.1890/100103

Arnett EB, Johnson GD, Erickson WP, Hein CD (2013a) A synthesis of studies to reduce at wind energy facilities in North America. Bat conservation international, Austin, Texas http://www.batsandwind.org/pdf/Operational\%20Mitigation\%20Synthesis\%20FINAL\%20 REPORT\%20UPDATED.pdf. Accessed 22 Dec 2014

Arnett EB, Hein CD, Schirmacher MR, Huso MMP, Szewczak JM (2013b) Evaluating the effectiveness of an ultrasonic acoustic deterrent for reducing. PLoS ONE 8(6):e65794. doi:10.1371/journal.pone.0065794

Arnett EB, Barclay RMR, Hein CD (2013c) Thresholds for bats killed. Front Ecol Environ 11:171. doi:10.1890/1540-9295-11.4.171

AronsonJB, Thomas AJ, Jordaan SL (2013) Bat fatality at a wind energy facility in the western Cape. Afr Bat Conserv News 31:9-12 (ISSN 1812-1268)

Baerwald EF, Barclay RMR (2009) Geographic variation in activity and fatality bats at wind energy facilities. J Mammal 90:1341-1349

Baerwald EF, Barclay RMR (2011) Patterns of activity and fatality bats at a wind energy facility in Alberta. J Wildl Manage 75:1103-1114

Baerwald EF, D'Amours GH, Klug BJ, Barclay RM (2008) Barotrauma is a significant cause of bat fatalities at wind turbines. Curr Biol 18(16):R695-R696

Baerwald EF, Edworthy J, Holder M, Barclay RMR (2009) A large-scale mitigtion experiment to reduce at wind energy facilities. J Wildl Manage 73:1077-1081

Baerwald EF, Patterson WP, Barclay RMR (2014) Origins patterns of bats killed in southern Alberta: evidence from stable isotopes. Ecosphere 5(article 118):1-17 
Barclay RMR, Harder LM (2003) Life histories of bats: life in the slow lane. In: Kunz TH, Fenton MB (eds) Bat ecology. University of Chicago Press, Chicago, pp 209-259

Bat Conservation Ireland (2012) Wind turbine/wind development bat survey guidelinesversion 2.8. Bat conservation Ireland http://www.batconservationireland.org/pubs/ reports/BCIreland\%20Wind \%20Farm\%20Turbine $\% 20$ Survey $\% 20$ Guidelines $\% 20$ Version\%202\%208.pdf. Accessed 20 January 2015

Bateman GC, Vaughan TA (1974) Nightly activities of mormoopid bats. J Mammal 55:45-65

Behr O, von helversen O (2006) Gutachten zur Beein -trächtigung im freien Luftraum jagender und ziehender Fle -dermäuse durch bestehende Windkraftanlagen. Wirkungs -kontrolle zum Windpark "Rosskopf" (Freiburg i Br.) im Jahr 2005. Report to Regiowind GmbH \& Co., Freiburg

Bennett E (2012) Hepburn wind farm bird and bat mortality survey interim report 11th July 2011-9th Jan 2012. Elmoby ecology http://hepburnwind.com.au/downloads/Hepburn\%20 Wind\%20interim\%20report\%20Bird\%20\&\%20Bat\%20Monitoring.pdf. Accessed 25 Aug 2014

Berkhout V, Faulstich S, Görg P, Kühn P, Linke K, et al. (2013) Wind energy 2012. FraunhoferInstitut für Windenergie und Energiesystemtechnik. IWES, Kassel

Bernstein MA, Griffin J, Lempert R (2006) Impacts on energy expenditures of use. Technical report prepared for the energy future coalition, RAND Corporation, Santa Monica, CL

Boonman M, Limpens HJGA, La Haye MJJ, van der Valk M, Hartman JC (2013) Protocollen leermuisonderzoek bij windturbines. Rapport 2013.28, Zoogdiervereniging \& Bureau Waardenburg. $29 \mathrm{pp}+1$ bijlage

Boshamer JPC, Bekker JP (2008) Nathusius' pipistrelles (Pipistrellus nathusii) and other species of bats platforms in the Dutch sector of the North Sea. Lutra 51:17-36

Brinkmann R, Behr O, Niermann I, Reich M (2011) Entwicklung von Methoden zur Untersuchung und Reduktion des Kollisionsrisikos von Fledermausen an onshore-Windenergieanlagen. Schriftenreihe Institut fur Umweltplanung. Cuvillier Verlag Gottingen, p 457

Briones-Salas M, Peralta-Pérez My, García-Luis M (2013) Acoustic characterization of new species of bats for the state of Oaxaca. Theyra 4:15-32

Camina A (2012) At wind farms in-lessons to be learned. Acta Chirop 14:205-212

Canadian Environmental Assessment Act (2012) An ACT respecting the environmental assessment of certain activities and the prevention of significant adverse environmental effects. Assented to 29 June 2012, in force 06 July 2012. (Online). Government : Justice Laws http://laws-lois.justice.gc.ca/eng/acts/C-15.21/page-1.html. Accessed 6 Jan 2015

Ceballos G, Arroyo-Cabrales J (2012) Lista actualizada de los mamíferos de México 2012. Rev Mex Mastozoología 1:27-80

Ceballos G, Oliva G, coords. (2005) Los mamíferos silvestres de México. Comisión Nacional para el Conocimiento y Uso de la Biodiversidad y Fondo de Cultura Económica, México, $\mathrm{DF}$

Cryan PM (2008) Mating behavior as a possible cause of bat fatalities at wind turbines. J Wildl Manage 72:845-849

Cryan PM (2011) Wind turbines as landscape impediments to connectivity of bats. Environ Law 41:355-370

Cryan PM, Barclay RMR (2009) Causes of bat fatalities at wind turbines: hypotheses and predictions. J Mammal 90:1330-1340

Cryan PM, Brown AC (2007) Migration of bats past a remote island offers clues towards the problem of bat fatalities at wind turbines. Biol Conserv 139(1-2):1-11

Doty AC, Martin AP (2012) Assessment of bat and avian mortality at a pilot wind turbine at Coega, Port Elizabeth, Eastern Cape, South Africa. New Zeal J Zool. doi:10.1080/0301422 3.2012.741068

Dubourg-Savage M-J, Rodrigues L, Santos H, Georgiakakis P, Papadotou E, Bach L, Rydell J (2011) Patterns of comparing north and south. Poster and abstract. In: Conference on wind energy and environmental impacts, Trondheim, Norway, May 2011 
EUROBATS (2014) Report of the intersessional working group on wind turbines and bat populations. http://www.eurobats.org/sites/default/files/documents/pdf/Advisory_Committee/Doc. AC_.20.5.ReportIWGWindTurbines_0.pdf. Accessed 1 Aug 2015

Frick WF, Pollock JF, Hicks AC, Langwig KE, Reynolds DS, Turner GG, Butchkoski CM, Kunz TH (2010) An emerging disease causes regional population collapse of a common North American bat species. Science 329:679-682

Gannon MR, Kurta A, Rodríguez-Durán A, Willig MR (2005) Bats of Puerto Rico: an island focus and a Caribbean perspective. Texas Tech University Press, Lubbock

García-Grajales J, Silva AB (2012) Revisión al conocimiento de los murciélagos del estado de Oaxaca. Therya 3:277-293

Georgiakakis P, Kret E, Cárcamo B, Doutau B, Kafkaletou-Diez A, Vasilakis D, Papadatou E (2012) Bat fatalities at wind farms in north-eastern Greece. Acta Chirop 14:459-468

Cryan PM, Gorresen, PM, Hein CD, Schirmacher MR, Diehl RH, Huso MM, Hayman DTS, Fricker PD, Bonaccorso FJ, Johnson DH, Heist K, Dalton DC (2014) Behavior of bats at wind turbines. Proc Nat Acad Sci. doi:10.1073/pnas.1406672111

Government Accountability Office (GAO) (2005) Wind Power: impacts on wildlife and government responsibilities for regulating development and protecting wildlife. Report to Congressional Requesters, GAO-05-906, U.S. Government Accountability Office, Washington

Government of Alberta (2013) Bat mitigation framework for wind power development. In: Environment and sustainable resource development. Alberta, Canada

Grodsky SM (2010) Aspects of bird and bat mortality at a wind energy facility in southeastern Wisconsin: impacts, relationships, and cause of death. Thesis, University of Wisconsin, Madison

Grodsky SM, Behr MJ, Gendler A, Drake D, Dieterle BD, Rudd RJ, Walrath NL (2011) Investigating the causes of death for wind turbine-associated bat fatalities. J Mammal 92:917-925

Hall LS, Richards GC (1972) Notes on Tadarida australis (Chiroptera:Molossidae). Aust Mammal 1:46-47

Hayes MA (2013) Bats killed in large numbers at United States wind energy facilities. Bioscience 63:975-979

Hein CD, Gruver J, Arnett EB (2013) Relating pre-construction bat activity and post-construction bat fatality to predict risk at wind energy facilities: a synthesis. Bat conservation international, Austin, Texas http://www.batsandwind.org/pdf/Pre-\%20Post-construction\%20 Synthesis_FINAL\%20REPORT.pdf. Accessed 23 Dec 2014

Heinrich B (1993) The hot-blooded insects. Springer, Berlin

Horn J, Arnett EB, Kunz TH (2008) Behavioral responses of bats to operating wind turbines. J Wildl Manage 72:123-132

Hull CL, Cawthen L (2012) Bat fatalities at two wind farms in Tasmania, Australia: bat characteristics, and spatial and temporal patterns. New Zeal J Zool. doi:10.1080/03014223.2012.7 31006

Huso MMP (2011) An estimator of wildlife fatality from observed carcasses. Environmetrics 22:318-329. doi:10.1002/env.1052

Huso MMP, Dalthorp D (2013) Accounting for unsearched areas in estimating wind turbinecaused fatality. J Wildl Manage. doi:10.1002/jwmg.663

Hutson AM, Mickleburgh SP, Racey PA (2001) Global status and conservation action plan: microchiropteran bats. IUCN/SSC Chiroptera Specialist Group, Cambridge

Hutterer R, Ivanova T, Meyer-Cords C, Rodrigues L (2005) Bat migrations in Europe: a review of banding data and literature. Naturschutz und Biologische Vielfalt, Bonn 28:1-176

Ingersoll TE, Sewall BJ, Amelon SK (2013) Improved analysis of long-term monitoring data demonstrates marked regional declines of bat populations in the Eastern United States. PLoS ONE 8(6):e65907. doi:10.1371/journal.pone.0065907 
Inkley DB, Anderson MG, Blaustein AR, Burkett VR, Felzer B, Griffith B, Price J, Root TL (2004) Global climate change and wildlife in North America. Wildl Soc Tech Rev 04-1 (The Wildlife Society, Bethesda, Maryland)

Jain AA, Koford RR, Hancock AW, Zenner GG (2011) Bat mortality and activity at a northern Iowa wind resource area. Am Mid Nat 165:185-200

Johnson GD (2005) A review of bat mortality at wind-energy developments in the United States. Bat Res News 46:45-49

Johnson GD, Perlik MK, Erickson WP, Strickland MD (2004) Bat activity, composition, and collision mortality at a large wind plant in Minnesota. Wildl Soc Bull 32:1278-1288

Johnson JB, Gates JE, Zegre NP (2011) Monitoring seasonal bat activi ty on a coastal barrier island in Maryland, USA. Environ Monit Assess 173:685-699

Korner-Nievergelt F, Brinkmann R, Niermann I, Behr O (2013) Estimating bat and bird mortality occurring at wind energy turbines from covariates and carcass searches using mixture models. PLoS ONE 8(7):e67997. doi:10.1371/journal.pone.0067997

Kunz TH, Arnett EB, Erickson WP, Hoar AR, Johnson GD, Larkin RP, Strickland MD, Thresher RW, Tuttle MD (2007a) Ecological impacts of wind energy development on bats: questions, research needs, and hypotheses. Front Ecol Environ 5:315-324

Kunz TH, Arnett EB, Cooper BM, Erickson WP, Larkin RP, Mabee T, Morrison ML, Strickland MD, Szewczak JM (2007b) Methods and metrics for studying impacts of wind energy development on nocturnal birds and bats. J Wildl Manage 71:2449-2486

Ladle RJ, Firmino JVL, Malhado ACM, Rodríguez-Durán A (2012) Unexplored diversity and conservation potential of Neotropical hot caves. Conserv Biol 26:978-982

LEA (2010) Monitorização dos efeitos da Medida de Minimização de Mortalidade do Parque Eólico do Outeiro Relatório final. Laboratório de Ecologia Aplicada da Universidade de Trás-os-Montes e Alto Douro. Vila Real, 78 pp

Lehnert LS, Kramer-Schadt S, Schonborn S, Lindecke O, Niermann I, Voigt CC (2014) Wind farm facilities in Germany kill noctule bats from near and far. PLoS ONE 9(8):e103106. doi:10.1371/journal.pone.0103106

Limpens HJGA, Boonman M, Korner-Nievergelt F, Jansen EA, van der Valk M, La Haye MJJ, Dirksen S, Vreugdenhil SJ (2013) Wind turbines and bats in the Netherlands-measuring and predicting. Report 2013.12, Zoogdiervereniging \& Bureau Waardenburg. 77 pp +2 appendices

McLeish T (2002) Wind power. Nat N Eng 11:60-65

Miller A (2008) Patterns of avian and bat mortality at a utility-scalewind farm on the southern high plains. Thesis, Texas Tech University, Lubbock

National Research Council [NRC] (2007) Ecological impacts of wind-energy projects. National Academies Press, Washington

Natural England (2014) Natural England technical information note TIN051. Bats and onshore wind turbines, 3rd edn, March 2014 http://publications.naturalengland.org.uk/search?q=Bat $\mathrm{s}+$ and+onshore+wind+turbines\&num $=100$. Accessed 4 Jan 2015

Nicholls B, Racey PA (2009) The aversive effect of electromagnetic radiation on foraging batsa possible means of discouraging bats from approaching wind turbines. PLoS ONE 7:e6246. doi:10.1371/journal.pone.0006246

O'Shea TJ, Bogan MA, Ellison LE (2003) Monitoring trends in bat populations of the United States and Territories: status of the science and recommendations for the future. Wild Soc Bull 31:16-29

Ontario Ministry of Natural Resources (2011) Bats and bat habitats: guidelines for wind power projects. Ontario, Canada

Piorkowski MD, O'Connell TJ (2010) Spatial pattern of summer bat mortality from collisions with wind turbines in mixed-grass prairie. Am Mid Nat 164:260-269

Poerink BJ, Lagerveld S, Verdaat H (2013) Bat activity in the Dutch offshore wind farm OWEZ and PAWP. IMARES Report no. C026/13 / tFC report no. 20120402. The Fieldwork Company, Wageningen, Holland http://edepot.wur.nl/248979. Accessed 29 Nov 2014 
Rodrigues L, Bach L, Dubourg-Savage MJ, Karapandza B, Kovac D, Kervyn T, Dekker J, Kepel A, Bach P, Collins J, Harbusch C, Park K, Micevski B, Minderman J (2015) Guidelines for consideration of bats in wind farm projects - revision 2014. EUROBATS Publication Series no. 6 (English version). UNEP/EUROBATS Secretariat, Bonn, Germany, UNEP/EUROBATS Secretariat. http://www.eurobats.org/sites/default/files/documents/publications/publication_series/pubseries_no6_english.pdf. Accessed 1 Aug 2015

Rodríguez-Durán A (2009) Bat assemblages in the West Indies: the role of caves. In: Fleming TH, Racey P (eds) Island bats: evolution, ecology, and conservation. University of Chicago Press, Chicago, pp 265-280

Rollins KE, Meyerholz DK, Johnson GD, Capparella AP, Loew SS (2012) A forensic investigation into the etiology of bat mortality at a wind farm: barotrauma or traumatic injury? Vet Pathol 49:362-371

Roscioni F, Russo D, Di Febbraro M, Frate L, Carranza ML, Loy A (2013) Regional-scale modeling of the cumulative impact of wind farms on bats. Biodivers Conserv. doi:10.1007/ s10531-013-0515-3

Roscioni F, Rebelo H, Russo D, Carranza ML Di Febbraro M, Loy A (2014) A modeling approach to infer the effects of wind farms on landscape connectivity for bats. Landscape Ecol. doi 10.1007/s10980-014-0030-2

Rydell J, Bach L, Dubourg-Savage M, Green M, Rodrigues L, Hedenstrom A (2010a) Bat mortality at wind turbines in northwestern Europe. Acta Chirop 12:261-274

Rydell J, Bach L, Dubourg-Savage MJ, Green M, Rodrigues L, Hedenström A (2010b) Mortality of bats at wind turbines links to nocturnal insect migration? Euro J Wildl Res 56:823-827

Rydell J, Engström H, Hedenström A, Larsen JK, Pettersson J, Green M (2012) The effect of wind power on birds and bats: a synthesis report. Report 6511, Swedish Environmental Protection Agency, Stockholm, Sweden

Rydell J, Bach L, Bach P, Guia Diaz L, Furmankiewicz J, Hagner-Wahlsten N, Kyheröinen EM, Lilley T, Masing M, Meyer MM, Petersons G, Suba J, Vasko V, Vintulis V, Hedenström A (2014) Phenology of migratory bat activity across the Baltic Sea and the south-eastern North Sea. Acta Chirop 16:139-147

Santos H, Rodrigues L, Jones G, Rebelo H (2013) Using species distribution modelling to predict bat fatality risk at wind farms. Biol Conserv 157:178-186

Schlesinger ME, Mitchell JFB (1987) Climate model simulations of the equilibrium climate response to increased carbon dioxide. Rev Geophys 25:760-798

Smallwood KS (2013) Comparing bird and bat fatality-rate estimates among North American wind-energy projects. Wildl Soc Bull 37:19-33

Steffens R, Zophel U, Brockmann D (2004) 40th anniversary bat marking Centre Dresdenevaluation of methods and overview of results. Sachsisches Landesamt für Umwelt und Geologie, p 132

Strickland MD, Arnett EB, Erickson WP, Johnson DH, Johnson GD, Morrison ML, Shaffer JA, Warren-Hicks W (2011) Comprehensive guide to studying wind energy/wildlife interactions. National Wind Coordinating Collaborative, Washington http://www.batcon.org/pdfs/ wind/National\%20Wind\%20Coordinating\%20Collaborative\%202011_Comprehensive\%20 Guide $\% 20$ to $\% 20$ Studying $\% 20$ Wind $\% 20$ Energy $\% 20$ and\%20Wildlife $\% 20$ Interactions.pdf. Accessed 4 Jan 2015

U.S. Fish and Wildlife Service (2012) Land-based wind energy guidelines. U.S. fish and wildlife service, Arlington, VA, USA http://www.fws.gov/windenergy/docs/WEG_final.pdf. Accessed 1 February 2015

Van der Meij T, Van Strien AJ, Haysom KA, Dekker J, Russ J, Biala K, Bihar Z, et al. (2014) Return of the bats? A prototype indicator of trends in European bat populations in underground hibernacula. Mammal Biol. doi:10.1016/j.mambio.2014.09.004

Villegas-Patraca R, Macías-Sánchez S, MacGregor-Fors I, Muñoz-Robles C (2012) Scavenger removal: bird and bat carcass persistence in a tropical wind farm. Acta Oecol 43:121-125

Voigt CC, Popa-Lisseanu AG, Niermann I, Kramer-Schadt S (2012) The catchment area of wind farms for European bats: a plea for international regulations. Biol Conserv 153:80-86 
Voigt CC, Lehnert LS, Petersons G, Adorf F, Bach L (2015a) Wildlife and renewable energy: German politics cross migratory bats. Eur J Wildl Res (in press)

Voigt CC, Aguirre L, Phelps K, Schoeman C, Vanitharani J, Zubaid A (2016) Bats and buildings: the conservation of synanthropic bats. In: Voight $\mathrm{CC}$, Kingston $\mathrm{T}$ (eds) Bats in the anthropocene: conservation of bats in a changing world. Springer International AG, Cham, pp. $427-453$

Weller TJ, Baldwin JA (2012) Using echolocation monitoring to model bat occupancy and inform mitigations at wind energy facilities. J Wildl Manage 76:619-631

Wellington WG (2011) The effects of variations in atmospheric pressure upon insects. Can J Res 1946, 24d(2):51-70

Young DP, Bay K, Nomani S, Tidhar WL (2011) Nedpower mount storm wind energy facility post-construction avian and bat monitoring: July-October 2010. Western EcoSystems Technology, Inc, Cheyenne, Wyoming http://www.batsandwind.org/pdf/WV\%20-\%20 Young\%20et\%20al.\%202011\%20-\%20Mount\%20Storm\%20Fall\%202010\%20Report(\%20 2-10-11).pdf. Accessed 4 Jan 2015 